Volume $17 \cdot$ Number 5

\title{
Parkinsonism: onset, progression, and mortality
}

\author{
Margaret M. Hoehn, M.D., and Melvin D. Yahr, M.D.
}

PARKINSONISM, described in its entirety over
one hundred and fifty years ago, ${ }^{1}$ rarely pre-
sents itself as a diagnostic problem. In conse-
quence, little scrutiny has been directed to the
marked variability of this frequently encoun-
tered neurological syndrome and to the progres-
sion of the disease in large groups of patients.
As with most chronic neurological disorders,
marked diversity can be expected to exist in
age and mode of onset, relative prominence
of the cardinal signs and symptoms, rate of
progression, and resultant degree of functional
impairment. Controversy over the effectiveness
of therapeutic measures for parkinsonism is
due partially to this wide variability and to
the paucity of clinical information about the
natural history of the syndrome. It is also re-

From the Department of Neurology, College of Physicians and Surgeons, Columbia University, and the Neurological Service, New York Neurological Institnte of the Columbia-Presbyterian Medical Center, New York City Read in part at the seventeenth annual meeting of the American Academy of Neurology in Cleveland, Ohio, on April 30,1965

Supported by a United States Public Health Service grant (NB 05184 ) and contract ( $\mathrm{PH}$ 43-64-54)

Dr. Hoehn's address is Neurological Institute, 710 West 168th Street, New York, New York 10032. lated to differences in terminology regarding the type of parkinsonism and the degree of its severity at the time of treatment. Consequently, it is difficult to determine whether treatment really influences the course of the disease and to what extent symptomatic relief is significant. It seems clear that, at a time when many new approaches to the treatment of parkinsonism are being suggested, information of this sort is of paramount importance.

With this in mind, a study was made of 856 patients bearing the diagnosis of paralysis agitans, Parkinson's disease, or parkinsonism who were seen at the Vanderbilt Clinic of the Columbia-Presbyterian Medical Center from 1949 to 1964, inclusively.

\section{MATERIAL AND METHODS}

From this group of 856 patients, 54 were excluded for the following reasons: 39 were found to have essential or familial tremor with none of the classical signs of parkinsonism, and 15 were omitted either because of incorrect diagnosis or because patients were lost to follow-up and insufficient information was available to establish a definite diagnosis of 
parkinsonism. The remaining 802 patients exhibited some or all of the accepted cardinal signs: "rest" tremor, plastic rigidity, paucity or delayed initiation of movement, slowness. and impaired postural and righting reflexes. The following data were recorded on all patients: age, sex, date of onset of parkinsonism, initial symptoms, age and date of death, duration of illness, and family history of parkinsonism or other neurological disease. During the two-year period 1963 and 1964, 263 of the patients were examined for additional or more detailed information, and $\mathrm{McBee}$ punch cards were used for recording 77 factors concerning past health, associated diseases, neurological signs, progression of disease, and degree of disability.

In any study of a chronic disease statistical problems arise because of sampling distortion. Patients may be omitted from the group being studied either because they died of other causes before seeking medical attention for their parkinsonism or because during the years of a lengthy illness they stopped attending the clinic and are lost to follow-up. These errors were partially corrected by including in progression and mortality analyses only those 271 patients who were first seen within two years of the onset of parkinsonism and by extensive tracing of lost patients. Supplementary information has been gained from death certificates, private physicians and relatives, and hospital and nursing home records. Autopsy findings, when available, were correlated with entries on death certificates. Statistical significance was determined by subjecting all data to the chi-square test or by calculations based on the standard error of differences between means and proportions using the Student's " $t$ " tables.

\section{CLASSIFICATION}

For this review, the classification of the syndrome of parkinsonism was based on a combination of clinical data and presumed etiology. An attempt was made to name and define each type of parkinsonism in such a manner as to be clinically applicable while recognizing that it might not necessarily be pathologically distinct from other types.

Primary parkinsonism or Parkinson's disease: The term "Parkinson's disease" is equated to "paralysis agitans" and has been reserved for what, at present, is considered the primary or "idiopathic" form of the disease. Six hundred and seventy-two patients were so classified after thorough review of their histories failed to reveal a disease process that could be considered etiologic in the production of their parkinsonism. The presence of associated neurologic abnormalities, unless clearly attributable to an independent disease process (such as cervical spondylosis or peripheral nerve injury) excluded the case from this diagnostic category.

The mean age at onset of the disease in these patients was 55.3 years (Table 1) and is in accord with previous reports. ${ }^{2-13}$ Although the range is wide, in two-thirds of the patients the disease began between the ages of 50 and 69 (Table 2). In Manschot's review in $1904^{5}$ the onset in $65.9 \%$ of his patients also occurred between the ages of 51 and 70. In the present study there were 268 women, with a mean age at onset of 54.8 years, and 404 men,

TABLE 1

PARKINSONISM: AGE AT ONSET

\begin{tabular}{|c|c|c|c|}
\hline \multirow{2}{*}{$\begin{array}{l}\text { Number } \\
\text { of cases* }\end{array}$} & \multirow[b]{2}{*}{ Type of parkinsonism } & \multirow{2}{*}{\multicolumn{2}{|c|}{ Mean at onset (years) }} \\
\hline & & & \\
\hline 672 & $\begin{array}{l}\text { A. Primary parkinsonism: Parkinson's disease } \\
\text { B. Secondary parkinsonism associated with: }\end{array}$ & $55.3 \pm 11.3$ & 17 to 89 \\
\hline 96 & (1) Encephalitis lethargica & $28.2 \pm 8.8$ & 12 to 53 \\
\hline$(82)$ & Definite & $28.3 \pm 9.1$ & 12 to 53 \\
\hline (14) & Probable & $27.9 \pm 7.2$ & 14 to 39 \\
\hline 22 & (2) Other & $49.3 \pm 14.8$ & 14 to 69 \\
\hline 12 & $\begin{array}{l}\text { C. Indeterminate parkinsonism associated with: } \\
\text { Encephalitis lethargica }\end{array}$ & $50.3 \pm 7.7$ & 40 to 66 \\
\hline
\end{tabular}

*A total of 802 cases of parkinsonism, at the Neurology Clinic, Columbia-Presbyterian Medical Center, I9491964, inclusively 
with a mean age at onset of 55.6 years. This difference is not significant and is in contrast to most other studies reporting the age at onset to be slightly lower in men than in women. ${ }^{6,8,10}$ In addition, the distribution of ages at onset is the same for both sexes.

During the fifteen years from 1949 to 1964 there has been a gradual increase in the proportion of older patients attending the clinic, a finding consistent with other reports. ${ }^{9,12}$ The mean age at onset has risen from 50.9 years in those patients first seen in 1949 to 58.3 years in those first seen in the 1960-1964 period. Similarly, the age at first examination in the Neurology Clinic has risen from 54.3 years in 1949 to 61.9 years in 1960-64. The gradually shifting proportions of the age distribution are illustrated in Figure 1 according to the year the patients were first examined. During this same period the time interval between the onset of parkinsonism and the first medical examination at the clinic has remained approximately constant for those patients whose age at onset was over 55 years (Fig. 2). However, patients who were younger when the disease began have been waiting longer in recent years before attending the clinic: from a mean of 3.5 years in 1949 to six years in 1960-1964. This contributes to the shift to older ages in recent years, as might the increasing age of the population as a whole. The increasing interval between onset and first clinic attendance does not seem to be related to decreasing severity of the disease in young patients, and it may well be that other socioeconomic factors play a role.

Secondary parkinsonism: Patients are in-

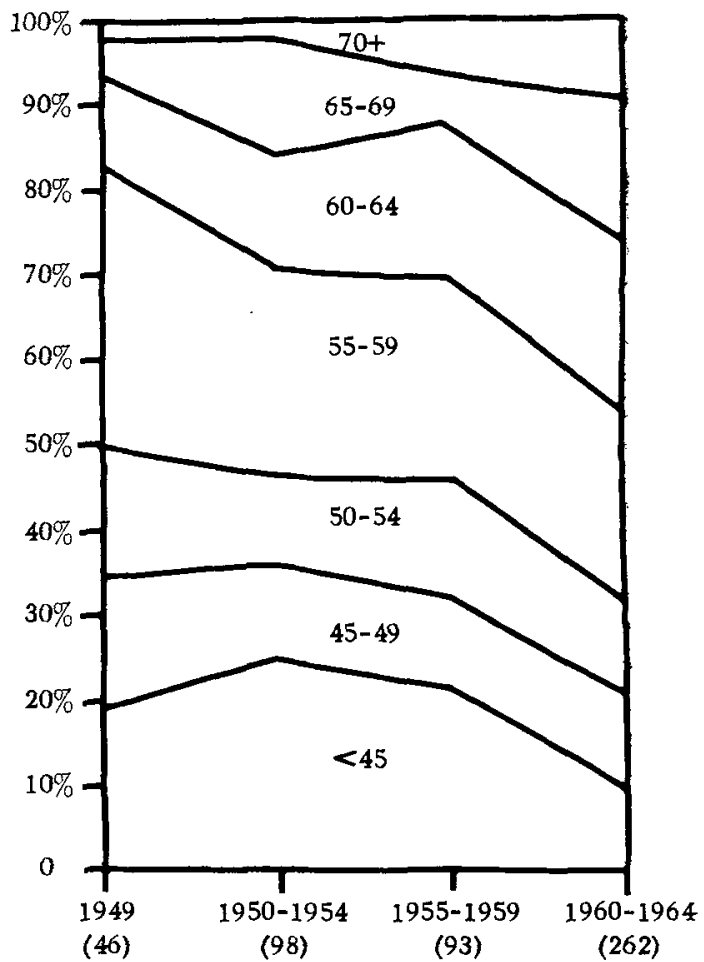

YEAR OF FIRST EXAMINATION

Fig. 1. Distribution of ages at onset of primary parkinsonism in 499 patients first seen at the Neurology Clinic, Columbia-Presbyterian Medical Center

cluded in this group if their parkinsonism is associated with a presumptive etiologic agent and/or signs which suggest that their parkinsonism is a fragment of a more diffuse disease of systems not ordinarily involved in the classical syndrome.

TABLE 2

PRIMARY PARKINSONISM*: DISTRIBUTION OF AGE AT ONSET BY SEX

\begin{tabular}{|c|c|c|c|c|c|c|}
\hline \multirow[b]{2}{*}{ Age at onset } & \multicolumn{2}{|c|}{ Men } & \multicolumn{2}{|c|}{ Women } & \multicolumn{2}{|c|}{ Total men and women } \\
\hline & No. & $\%$ & No. & $\%$ & No. & $\%$ \\
\hline Under 30 & 7 & 1.7 & 5 & 1.9 & 12 & 1.8 \\
\hline $30-39$ & 29 & 7.2 & 27 & 10.1 & 56 & 8.3 \\
\hline $40-49$ & 72 & 17.8 & 44 & 16.4 & 116 & 17.3 \\
\hline $50-59$ & 143 & 35.4 & 94 & 35.1 & 237 & 35.3 \\
\hline $60-69$ & 112 & 27.7 & 77 & 28.7 & 189 & 28.1 \\
\hline $70-79$ & 39 & 9.7 & 19 & 7.1 & 58 & 8.6 \\
\hline \multirow[t]{2}{*}{$80+$} & 2 & 0.5 & 2 & 0.7 & 4 & 0.6 \\
\hline & $\overrightarrow{404}$ & & $\overline{268}$ & & $\overline{672}$ & \\
\hline
\end{tabular}

*672 cases of primary parkinsonism, Neurology Clinic, CPMC, 1949-1964, inclusively 


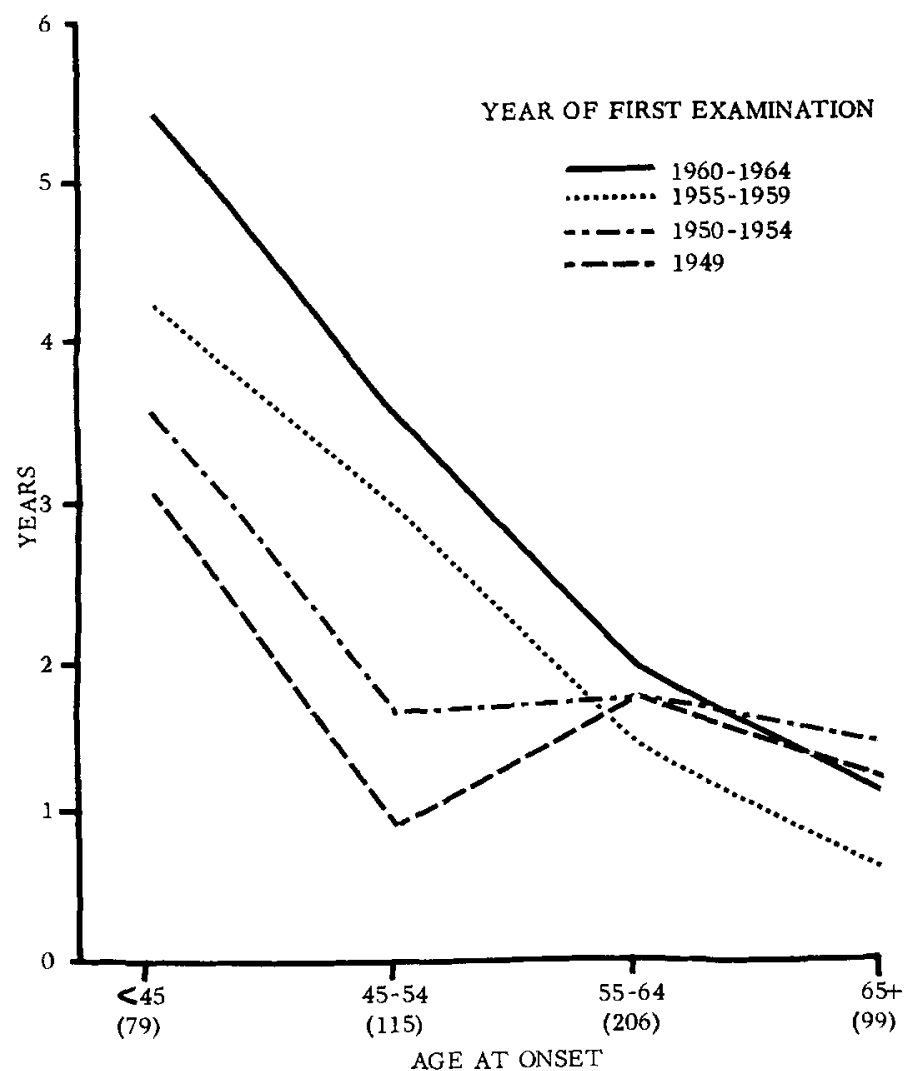

Fig. 2. Mean intervals in years between onset of disease and first examination for various ages at onset in 499 patients with primary parkinsonism
1] Postencephalitic parkinsonism. Still the largest subgroup of patients with secondary parkinsonism is that in which the syndrome developed following encephalitis lethargica. Eighty-two patients with a definite history of sleeping sickness and its characteristic sequelae or its pathognomonic stigmata, oculogyria and palilalia, are classified as "definite" postencephalitic parkinsonism (Table 1). There is a small group of 14 patients with a less definite history of sleeping sickness and without oculogyria who, nevertheless, exhibit other nonpathognomonic but frequent sequelae of encephalitis lethargica; these include oculomotor and other cranial nerve palsies, pyramidal tract signs, dystonic phenomena, sleep disturbances, personality changes, and autonomic dysfunction. These patients are designated "probable" postencephalitic parkinsonism and share with the "definite" group a similarly young mean age at onset. It is not to be inferred from these figures that the onset of parkinsonism following encephalitis lethar- gica was confined to the young. By including only those patients still alive at the beginning of the review period, 1949-1964, a selective factor was introduced into this study.

Of the total of 802 cases of parkinsonism which were reviewed, there was none with a definite past history of encephalitis of a type other than von Economo's. In addition, a history of influenza in the post-World War I epidemic without encephalitis or postencephalitic symptoms was not considered significant. ${ }^{13,14}$ Seventy-three (15.2\%) of the 480 patients with primary parkinsonism and 15 (15.6\%) of the 96 with the postencephalitic syndrome who were born before 1920 had had influenza. These patients differed in no way from those with parkinsonism but without a history of influenza.

Because of the strict criteria for classification as secondary parkinsonism due to encephalitis lethargica, two types of patients with this initial diagnosis were removed from this category and reclassified: 
a] In reviewing charts, it was found that many patients, when first seen in the 1930's and 1940's, had been diagnosed as postencephalitic parkinsonism only because the onset of disease occurred at an early age. However, even though encephalitis is not excluded as an etiologic factor, these patients do not fulfill the present criteria for such a diagnosis. They have no history of encephalitis lethargica or any other infectious illness which might be confused with it; they have neither the pathognomonic sequelae (oculogyria and palilalia) nor the other common neurologic sequelae of encephalitis lethargica. Clinically, they are in no way different from patients seen more recently with an early age of onset who are now classified as primary parkinsonism, and in this study they are included in that group.

b] A second group of 12 patients has been excluded for the present from the postencephalitic category. These have parkinsonism with an uncertain relationship to a past history of encephalitis lethargica and will be discussed under the section on indeterminate parkinsonism.

2] Other causes of secondary parkinsonism. There is a final group of 22 patients whose parkinsonian symptomatology is a manifestation of a definable process, such as arteriosclerosis, diffuse central nervous system degenerative disease, intoxication, metabolic defect, tumor, and the use of drugs. The patients in this group had unequivocal symptoms and signs of parkinsonism, often in association with signs of other, more diffuse, neurologic involvement believed to be on the same etiologic or pathologic basis as the parkinsonism. They form a heterogeneous group which included 14 cases of parkinsonism occurring in association with other extrapyramidal dyskinesias, such as dystonic posturing, torticollis, facial grimacing, and mild athetosis. The pathologic lesion in one of these patients was a deeply situated arteriovenous malformation; in another the onset was apoplectic; a third had accompanying cerebellar abnormalities; and a fourth, corticospinal involvement with severe dementia in addition to the extrapyramidal dysfunction. Five of the 22 patients had cerebellar system abnormalities such as ataxia, dysmetria, and severe intention tremor in addition to their parkinsonism. Two patients had associated corticospinal involvement; one was traumatic in origin and the other was thought to be due to vascular insufficiency.

Indeterminate parkinsonism: In a certain number of patients it is impossible to determine whether the parkinsonism is primary or secondary. It is associated with other neurologic disease, either by history or by present signs, and there is no indication whether this association is causatively and pathologically determined or whether it is merely coincidental. In many, the differentiation may be possible only after long-term observation. For example, the present series of patients included 12 with a convincing history of encephalitis lethargica followed by an apparently complete recovery which lasted from ten to forty-one years (mean 24.7) without evidence of neurologic or psychologic sequelae. The present disease in these patients is indistinguishable from primary parkinsonism, and they have no oculogyria, palilalia, cranial nerve palsies, or other neurologic abnormalities usually associated with the postencephalitic syndrome. The mean age at onset of their disease was 50.3 years. They have been called "indeterminate" because of the query whether their parkinsonism is a true postencephalitic phenomenon or merely a coincidental and unrelated condition. There is also the possibility that the retrospective diagnosis of encephalitis lethargica is in error. This is an interesting group of patients, and pathological studies eventually may help to resolve the problem. An example follows:

Case report. A male patient had had influenza in 1918 and definite encephalitis lethargica in 1919, followed by several years of emotional instability. He made a complete neurologic and psychologic recovery and remained perfectly well for forty years until, at age 51 , he developed generalized slowness followed by bilateral upper extremity tremor. Over the next five years there was moderate progression, with severe paraspinal rigidity, a Simian posture, soft monotonous speech, facial masking, and bradykinesia. He had no oculogyria, palilalia, oculomotor or other cranial nerve palsies, or autonomic dysfunction. He died as a result of a myocardial infarction five years after the onset of parkinsonism. Unfortunately no autopsy was obtained.

\section{SIGNS AND SYMPTOMS}

Initial symptoms in patients who were interviewed and examined in detail are listed in 
Table 3. Complaints such as muscle pain and aching, paresthesias, and generalized fatigue were designated the initial symptom only when they were specifically and unequivocally related to the onset of parkinsonism. As in Mjönes' and Hartmann's studies, ${ }^{15,16}$ tremor was the most frequent initiating symptom, occurring in $70 \%$ of patients with primary parkinsonism and in over $50 \%$ of the patients with postencephalitic parkinsonism in the present study. Among patients who were first seen within two years of the onset of their disease, tremor was the first symptom in 59.3\%. There were few differences in initial symptomatology among the various types of parkinsonism, except that speech, psychiatric, and sleep disturbances were more frequent in the postencephalitic patients than in those with "idiopathic" parkinsonism.

As expected, $3,8,17-19$ tremor and rigidity

TABLE 3

INITIAL SYMPTOMS

\begin{tabular}{|c|c|c|}
\hline Initial Symptom & $\begin{array}{c}\text { Number o } \\
\text { Primary } \\
\text { parkinsonism } \\
\text { (I83 cases) }\end{array}$ & $\begin{array}{l}\text { Patients- } \\
\text { Post- } \\
\text { encephaditic } \\
\text { parkinsonism } \\
\text { (44 cases) }\end{array}$ \\
\hline Tremor & 129 & 23 \\
\hline Gait disturbance & 21 & 8 \\
\hline Stiffness & 18 & 7 \\
\hline Slowness & 18 & 6 \\
\hline $\begin{array}{l}\text { Muscle pain, cramps, } \\
\text { aching }\end{array}$ & 15 & 2 \\
\hline Loss of dexterity & 14 & 3 \\
\hline Handwriting disturbance & 9 & 0 \\
\hline $\begin{array}{l}\text { Depression, nervousness, or } \\
\text { other psychiatric } \\
\text { disturbance }\end{array}$ & or & 5 \\
\hline Speech disturbance & 7 & 12 \\
\hline $\begin{array}{l}\text { General fatigue, muscle } \\
\text { weakness }\end{array}$ & 5 & 6 \\
\hline Drooling & 3 & 2 \\
\hline Loss of arm swing & 3 & 2 \\
\hline Facial masking & 3 & 0 \\
\hline Dysphagia & 1 & 0 \\
\hline Paresthesia & 1 & 0 \\
\hline Drowsiness & 0 & 6 \\
\hline $\begin{array}{l}\text { Percent of patients with } \\
\text { tremor as an initial } \\
\text { symptom }\end{array}$ & $70.5 \%$ & $52.3 \%$ \\
\hline $\begin{array}{l}\text { Average number of initial } \\
\text { symptoms per subject }\end{array}$ & 1.4 & 1.9 \\
\hline
\end{tabular}

were the most frequent physical findings. Only $10 \%$ of patients were free of tremor and $10 \%$ were free of rigidity. Five percent of patients had an intention component to the classical sustention and rest tremor but none had a pure intention tremor. Other frequent physical findings were delayed initiation and slowness of movement; loss of associated and spontaneous movements; facial hypomimia; various gait disturbances, such as shuffling, festination, and pulsion; impairment of rapid alternating and succession movements of affected limbs; various speech disturbances, generally characterized by monotony and low volume and less frequently by dysarthria; and impaired righting reflexes.

Postural deformities were frequent, especially among the more advanced cases. These included Simian posture, lateral tilt of the trunk, flexion of the forearm, ulnar deviation of fingers flexed at the metacarpophalangeal joints and hyperextended at the proximal and distal interphalangeal joints, and inversion with plantar flexion of the feet. An interesting finding was the presence of brisk palmomental reflexes without other reflex abnormalities; this occurred in $60 \%$ of the patients with Parkinson's disease and in $30 \%$ of those with postencephalitic parkinsonism. Fourteen percent of patients had evidence of a mild-to-moderate organic mental syndrome which was usually characterized by recent memory defects and some impairment of judgment and insight. No attempt was made in this study to differentiate the changes in mental status which are part of the disease from those produced by drugs. Four percent of patients were moderately to severely depressed.

All patients in this series had the signs and symptoms necessary for an unequivocal diagnosis of the syndrome of parkinsonism, regardless of the etiology, type, or severity. However, on occasion, when the full syndrome is not present, uncertainties may arise in making this diagnosis. Especially when only tremor is present confusion may arise between parkinsonism and essential or heredofamilial tremor. Because the pathophysiologic distinction is still indefinite, an arbitrary clinical distinction has been accepted utilizing the following generally established criteria for essential tremor: ${ }^{20-25}$ [1] onset at any age, with or without a fam- 
ily history of tremor, [2] most frequently a sustention tremor with a terminal exaggeration-often a frank intention tremor, [3] upper extremities, head, tongue, and lips are the most frequent sites of involvement, with trunk and lower extremities rarely affected, and [4] generally considered a delimitable monosymptomatic condition, although a minimal amount of rigidity is occasionally reported.

More precise elucidation of the characteristics and the patterns of progression of each sign is needed, together with standardization of criteria for the diagnosis of definite, probable, and possible parkinsonism. The various classical signs often progress at independent rates in the individual patient, and the clinical picture of one may be dominated by tremor, of another by rigidity or akinesia. It has been our impression that those patients whose chief complaint is tremor have a slightly better prognosis than those whose akinesia or rigidity is the main manifestation.

\section{DEGREE OF DISABILITY}

Because of the variability with which the syndrome evolves, in evaluating the results of therapy it is essential to consider not only the type of parkinsonism and its chief manifestations but also the extent of disability at the time of treatment and the rate of progression before and after treatment. Each case was rated on an arbitrary scale (Stages I-V) based on the level of clinical disability.

Stage I. Unilateral involvement only, usually with minimal or no functional impairment.

Stage $I I$. Bilateral or midline involvement, without impairment of balance.

Stage III. First sign of impaired righting reflexes. This is evident by unsteadiness as the patient turns or is demonstrated when he is pushed from standing equilibrium with the feet together and eyes closed. Functionally the patient is somewhat restricted in his activities but may have some work potential depending upon the type of employment. Patients are physically capable of leading independent lives, and their disability is mild to moderate.

Stage IV. Fully developed, severely disabling disease; the patient is still able to walk and stand unassisted but is markedly incapacitated.

Stage V. Confinement to bed or wheelchair unless aided.

While not necessarily intimating pathophysiologic correlation, this method of staging is practical and allows for reproducible assessments by independent examiners of the general functional level of the patient. It is not applicable only in isolated instances, as, for example, in patients with such severe rigidity that they are incapacitated even though righting reflexes remain intact. On the other hand, the general experience has been that it is the onset of disturbances of balance which heralds severe disability. Similarly, there are occasional patients who are more incapacitated by severe unilateral disease than are others by milder bilateral disease. Such severe unilateral involvement, however, is more frequently found in the long-standing postencephalitic patients and is rare in those with Parkinson's disease. Patients with the latter usually develop bilateral signs before disability is marked. Not infrequently, Stage $I$ is skipped and the onset is bilateral or generalized.

One hundred and eighty-three of the patients examined in detail during 1963 and 1964 had primary parkinsonism. The stages of disease in these patients are shown in Table 4. In this clinic population, three-quarters are equally divided in Stages II, III, and IV; a smaller number is found in Stage I, and only a handful is included in Stage V. In a study by

TABLE 4

PRIMARY PARKINSONISM: STAGE AND DURATION OF ILLNESS

\begin{tabular}{|c|c|c|c|c|c|c|c|c|c|}
\hline \multirow{2}{*}{$\begin{array}{c}\text { Total } \\
\text { patients } \\
\text { (183) }\end{array}$} & \multirow[b]{2}{*}{ Stages } & \multirow[b]{2}{*}{ Median } & \multirow[b]{2}{*}{$0-4$} & \multirow[b]{2}{*}{$5-9$} & \multirow{2}{*}{$\begin{array}{c}\text { Duration (Years) } \\
10-14\end{array}$} & \multirow{2}{*}{$15-19$} & \multirow[b]{2}{*}{$20-24$} & \multirow[b]{2}{*}{$25-29$} & \multirow[b]{2}{*}{$30+$} \\
\hline & & & & & & & & & \\
\hline 31 & I & $3.0 \pm 7.1$ & 20 & 6 & 3 & 1 & 0 & 0 & 1 \\
\hline 53 & II & $6.0 \pm 6.9$ & 24 & 14 & 9 & 3 & 1 & 1 & 1 \\
\hline 43 & III & $7.0 \pm 6.3$ & 15 & 14 & 9 & 4 & 0 & 0 & 1 \\
\hline 47 & IV & $9.0 \pm 7.2$ & 11 & 18 & 10 & 4 & 2 & 1 & 1 \\
\hline 9 & $V$ & $14.0 \pm 3.4$ & 0 & 2 & 5 & 2 & 0 & 0 & 0 \\
\hline
\end{tabular}


Mjönes, ${ }^{15} 103$ of 258 patients (39.9\%) developed severe disease within the first four years of illness; the criterion of severe disease was impairment of work ability and, in this series, corresponds to Stage III, the beginning of disability. At the time of examination in the present study, 26 of 70 patients (37.1\%) whose illness had been present less than five years had reached Stage III or beyond, a proportion quite similar to that of Mjönes. Of all patients who had had their illness ten years or longer, 33.9\% (20 of 59) were still found in Stages I and II; these correspond to the "mild" cases of Mjönes, who found 20\% of the patients in this category. We refer to them as having atypical primary parkinsonism. The signs of parkinsonism, although generalized, were mild for many years, or they remained confined to one or to both extremities on the same side of the body. These patients demonstrate nothing incompatible with a diagnosis of classical primary parkinsonism, and there is no indication at present that they represent anything but a milder form of the syndrome. The limits of the atypical group are defined by: [1] the preservation of righting reflexes and balance for at least ten years of illness and [2] minimal disability until after twenty years of illness.

As might be anticipated, the more severe stages are associated with longer duration of disease (Table 4). There is considerable variation, however, in the duration of illness for all patients at a given stage. Furthermore, the omission of the experience of other patients, living or deceased, who are no longer attending the clinic, as well as the prior experience of the subjects examined during this period, make this table unsuitable for projecting the progression from stage to stage. However, it is descriptive of the clinic population at a given time.

Among the postencephalitic patients attending the clinic only $25 \%$ are severely disabled after twenty years of illness. This agrees with the clinical impression ${ }^{13,14}$ that the disease of most postencephalitic patients still alive today seems to have reached a plateau beyond which minimal progression occurs.

\section{PROGRESSION OF DISABILITY}

By definition, the patients in Stages I, II, and III are only minimally disabled, whereas patients in IV and V are severely disabled. Therefore, this is usually a convenient method of assessing the progression of functional incapacity. Table 5 indicates the fate of 271 patients with Parkinson's disease or primary parkinsonism seen at the Neurology Clinic from January 1949 to December 1964, inclusively. Only those patients seen within two years of the onset of their disease are included. Almost two-thirds of the patients still living were examined to determine the stage of their disease. Information on the remainder was obtained from other hospitals, nursing homes, and medical reports, as well as by telephone communication with the patient or family. Although the specific stage could not always be determined, patients were considered disabled if they were confined to bed or wheelchair (Stage V) or if they were unable to feed or clothe themselves or leave their homes unaided (Stage IV).

Among patients first observed within the last five years, over one-quarter are either dead or disabled. This proportion rises to $60 \%$ of those first observed five to nine years ago, to over $80 \%$ of those first observed ten to fourteen

TABLE 5

EXTENT OF DISABILITY AND DEATH AMONG 271 PATIENTS WITH PRIMARY PARKINSONISM*

\begin{tabular}{lccccc}
\hline Year of first observation & Lost & $\begin{array}{c}\text { Number } \\
\text { followed }\end{array}$ & Dead & Disabled $\dagger$ & $\begin{array}{c}\text { Percentage dead } \\
\text { and disabledt }\end{array}$ \\
\hline 1960 to 1964 & 0 & 110 & 15 & 16 & $28.1 \%$ \\
1955 to 1959 & 1 & 41 & 12 & 13 & $61.0 \%$ \\
1950 to 1954 & 4 & 48 & 28 & 12 & $83.3 \%$ \\
1949 & 6 & 19 & 13 & 4 & $89.5 \%$ \\
\hline
\end{tabular}

* 271 cases of primary parkinsonism seen within two years of onset of disease. Omitted: 42 cases first observed before 1949

†Stages IV and V 
years ago, and to almost $90 \%$ of those first observed fifteen years ago. At the time of the study the average duration of illness by history in these patients was one year longer than the period of observation.

Youth at onset is not necessarily a favorable prognostic sign. As in Schwab's study, ${ }^{11}$ an analysis of the proportion of patients who are dead or severely disabled based on their age at onset revealed no difference in progression during the first ten years of illness (Table 6). After ten years the higher incidence of death and disability among those with an onset after the age of $\mathbf{5 0}$ is largely attributable to a higher death rate in the older population, whose minimum age is 60 at this point.

On the other hand, sex of the patient, age at onset, duration of illness, severity, and rate of progression were analyzed in relation to the mode of onset in an attempt to determine whether there is any prognostic significance to the initiating symptom. As in other aspects of the disease, there are wide variations in each of these parameters and they were without definitely significant correlations. However, there is a suggestion that, at least during the first ten years of illness, the rate of progression of the disease may be slightly less

TABLE 6

EXTENT OF DEATH AND DISABILITY RELATED TO AGE AT ONSET OF PRIMARY PARKINSONISM*

\begin{tabular}{|c|c|c|c|c|c|}
\hline Year of first observation & Lost & $\begin{array}{l}\text { Number } \\
\text { followed }\end{array}$ & Dead & Disabled $\dagger$ & $\begin{array}{l}\text { Percent dead } \\
\text { and disabled }\end{array}$ \\
\hline \multicolumn{6}{|l|}{$1960-1964$} \\
\hline Under age 50 & 0 & 14 & 0 & 4 & $28.6 \%$ \\
\hline Age 50 and over & 0 & 96 & 15 & 12 & $28.1 \%$ \\
\hline \multicolumn{6}{|l|}{$1955-1959$} \\
\hline Under age 50 & 0 & 7 & 0 & 4 & $57.1 \%$ \\
\hline Age 50 and over & 1 & 34 & 12 & $\hat{\theta}$ & $61.8 \%$ \\
\hline \multicolumn{6}{|l|}{$1950-1954$} \\
\hline Under age 50 & 1 & 11 & 3 & 4 & $63.6 \%$ \\
\hline Age 50 and over & 3 & 37 & 25 & 8 & $89.2 \%$ \\
\hline \multicolumn{6}{|l|}{1949} \\
\hline Under age 50 & 0 & 7 & 3 & 2 & $71.4 \%$ \\
\hline Age 50 and over & 6 & 12 & 10 & 2 & $100.0 \%$ \\
\hline
\end{tabular}

*271 cases of primary parkinsonism seen within two years of onset of disease. Omitted: 42 cases first observed before 1949

† Stages IV and V

TABLE 7

EXTENT OF DEATH AND DISABILITY RELATED TO MODE OF ONSET OF PRIMARY PARKINSONISM*

\begin{tabular}{|c|c|c|c|c|c|}
\hline Year of first observation & Lost & $\begin{array}{l}\text { Number } \\
\text { followed }\end{array}$ & Dead & Disabled $\uparrow$ & $\begin{array}{l}\text { Percent dead } \\
\text { and disabled }\end{array}$ \\
\hline \multicolumn{6}{|l|}{$1960-1964$} \\
\hline Onset with tremor & 0 & 65 & 9 & 7 & $24.6 \%$ \\
\hline Other onset & 0 & 45 & 6 & 9 & $33.3 \%$ \\
\hline \multicolumn{6}{|l|}{$1955-1959$} \\
\hline Onset with tremor & 1 & 28 & 8 & 7 & $53.6 \%$ \\
\hline Other onset & 0 & 13 & 4 & 6 & $76.9 \%$ \\
\hline \multicolumn{6}{|l|}{$1950-1954$} \\
\hline Onset with tremor & 1 & 27 & 15 & 7 & $81.5 \%$ \\
\hline Other onset & 3 & 21 & 13 & 5 & $85.7 \%$ \\
\hline \multicolumn{6}{|l|}{1949} \\
\hline Onset with tremor & 5 & 8 & 4 & 3 & $87.5 \%$ \\
\hline Other onset & 1 & 10 & 8 & 1 & $90.0 \%$ \\
\hline
\end{tabular}

*271 cases of primary parkinsonism seen within two years of onset of disease. Omitted: 42 cases first observed before 1949 ; 1 case with unknown mode of onset

tStages IV and $V$ 
TABLE 8

AGE AT DEATH AND DURATION OF ILLNESS BEFORE DEATH

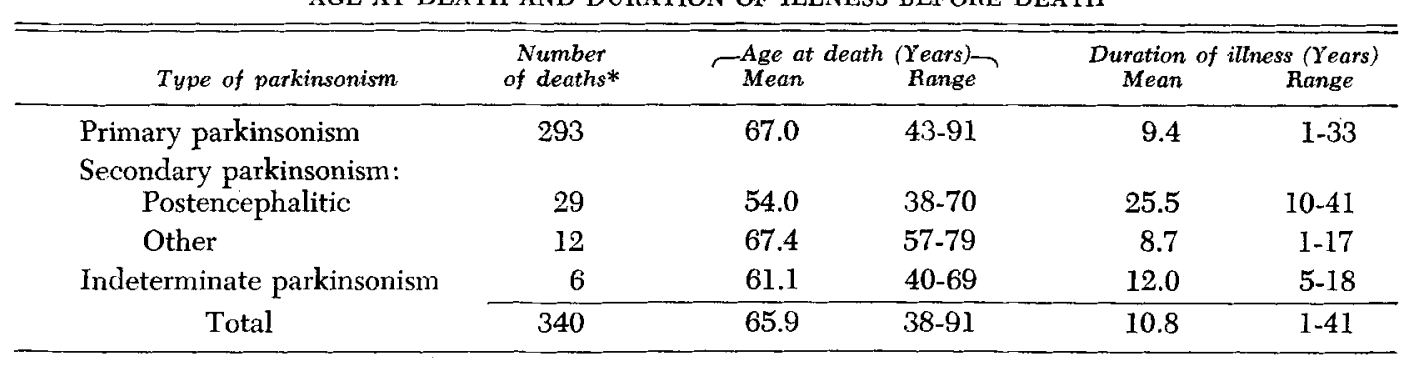

*340 deaths among 802 patients with parkinsonism

rapid when tremor is the initial symptom (Table 7). No significant relationships were found among: rate of progression of disease, sex of patient, family history of parkinsonism or other neurological disorder, other initial symptoms, and illnesses preceding the onset of parkinsonism.

\section{AGE AT' DEATH}

There have been 340 deaths among the 802 parkinsonian patients who have attended the clinic between 1949 and 1964. Table 8 indicates the ages at death and duration of illness before death for each type of parkinsonism. The ages at which illness began are not significantly different in these patients than in those who are still living with the same types of parkinsonism. Most striking are the wide ranges of the ages at death and of the durations of illness before death. The mean age at death is 65.9 years, which is similar to Mjönes' finding of 65 to 67 years, ${ }^{15}$ but lower than Kurland's (72 years). ${ }^{26}$ Although the age at death of the postencephalitic patients (54 years) is younger than the average for other patients, it does not differ from the age at death of those with a similar age at onset. Illness began before the age of 50 in 86 of all patients and after the age of 50 in 254 . The mean age at death for the young patients was 55.6 years (range, 38 to 77 ) after a mean duration of illness of 18.4 years (range, 2 to 41). For those patients with an onset at age 50 or older, the mean death age was 69.2 years (range, 59 to 91 ) after a mean duration of illness of 7.9 years (range, 1 to 30 ). There are no significant differences among the various types of parkinsonism in this regard. Therefore, the age of death seems to be a

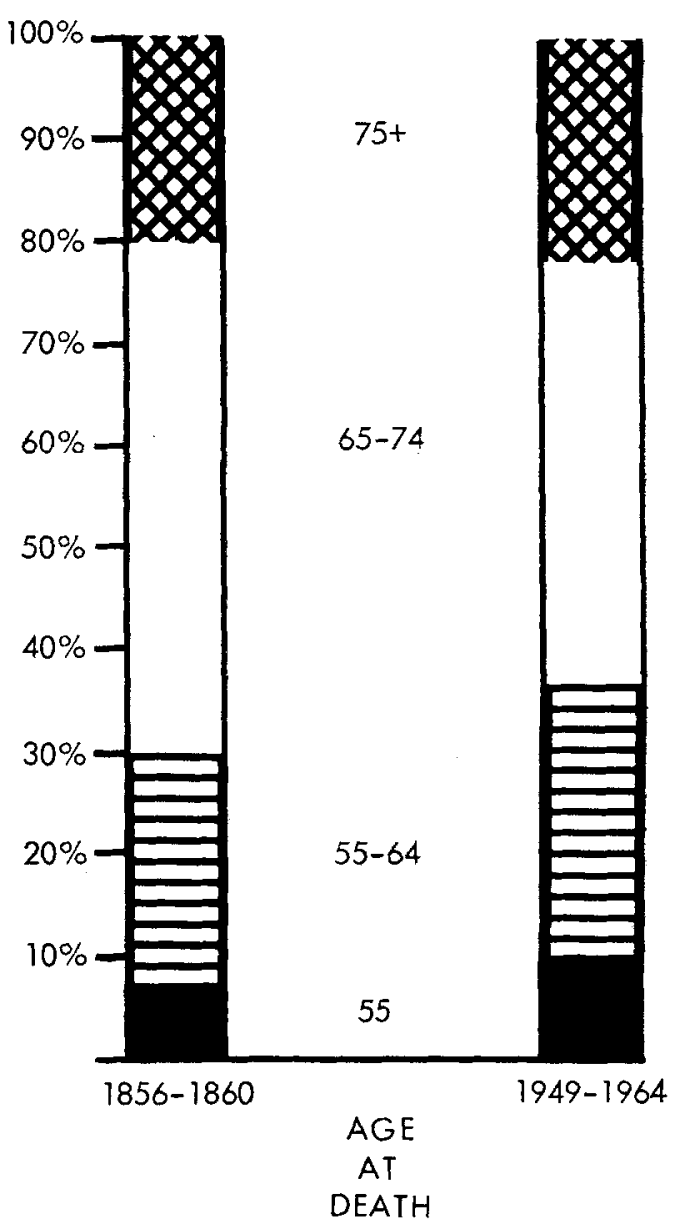

Fig. 3. Distribution of ages at death in primary parkinsonism. Comparison of 293 deaths among patients seen at the Columbia-Presbyterian Medical Center, 1949-1964, inclusively, with statistics obtained from the Registrar General's Reports of England and Wales for the years 1856 to 1860 
function of the age at onset of the illness rather than of the type of parkinsonism, with an increasingly younger age at death as the age at onset of the disease becomes younger. The mean duration of illness in those in whom it develops early is longer, but this is not sufficient to compensate.

The distribution of ages at death for primary parkinsonism is given in Figure 3. A sobering and discouraging fact emerges from a comparison of this distribution with the proportion of patients in the various age groups at the time of death obtained from the reports of the Registrar General of England and Wales one hundred years ago. ${ }^{27}$ Despite the addition of a variety of therapeutic measures for parkinsonism over these years, including numerous drugs, surgical procedures, and improved supportive care, the distribution of ages at death has remained essentially unchanged.

Whether or not there is a limitation of life expectancy can be determined by comparing the observed number of deaths with the expected number based on mortality from all causes in the United States during the period of this study (Table 9). ${ }^{28}$ As before, only those 271 patients seen within two years of the onset of their disease could be considered, and, among these patients, 30 were omitted because the interval of observation for study purposes was less than one year. In this group, there were 91 deaths between 1949 and 1964, inclusively. It can be seen that this mortality

TABLE 9

\section{MORTALITY IN PRIMARY PARKINSONISM*}

\begin{tabular}{|c|c|c|c|c|}
\hline \multirow{2}{*}{$\begin{array}{l}\text { Age at initial } \\
\text { examination } \dagger\end{array}$} & \multirow[b]{2}{*}{ Number $\ddagger$} & \multicolumn{2}{|c|}{ Deaths___ } & \multirow{2}{*}{$\begin{array}{l}\text { Ratio of } \\
\text { observed to } \\
\text { expected }\end{array}$} \\
\hline & & Observed & Expected\$ & \\
\hline Under 45 & 31 & 5 & 2.1 & 2.4 \\
\hline $45-49$ & 19 & 8 & 1.9 & 4.2 \\
\hline $50-54$ & 27 & 9 & 3.9 & 2.3 \\
\hline $55-59$ & 59 & 28 & 7.3 & 3.8 \\
\hline $60-64$ & 42 & 20 & 4.9 & 4.1 \\
\hline $65-69$ & 35 & 12 & 5.7 & 2.1 \\
\hline $70+$ & 28 & 9 & 5.5 & 1.6 \\
\hline Total & 241 & 91 & 31.2 & 2.9 \\
\hline
\end{tabular}

* 271 cases of primary parkinsonism observed within two years of the onset of disease

+ Approximately one year after onset

$\$ 30$ patients omitted because interval of observation was less than one year

§Calculated from U.S. Life Tables for Age-Sex-Color ${ }^{28}$ among parkinsonian patients is almost 3 times that of the life-table projectives of the general population of the same age, race, and sex distribution. The increased risk of mortality with parkinsonism is present from the beginning of the illness and is observed at all intervals after the onset of symptoms. Although the death rate is higher in men, ${ }^{29}$ the relative mortality risk in parkinsonian patients is slightly less in men ( 2.6 times the expected) than in women (3.8 times the expected). When tremor is the initial symptom the risk of mortality is 2.4 times that of other persons of like sex, age, and color in the general population. Prognosis is even less favorable among patients whose onset is with rigidity, slowness, or other non-tremor manifestations. In such patients there were 3.9 times as many deaths as expected. As can be seen graphically in Figure 4, this difference between patients with tremor and with other initial symptoms is most marked when the onset is under the age of 60 . As far as could be determined from the number of patients involved, there were also more than the expected number of deaths among those with a type of parkinsonism other than primary. There would seem to be little doubt that the state of "parkinsonism" as an entity severely limits life expectancy.

\section{CAUSES OF DEATH}

In primary mortality tabulations it is customary to select the "underlying cause of death" or "that disease or injury which initiated the train of morbid events leading directly to death," as defined by the World Health Organization's International Statistical Classification of Diseases, Injuries, and Causes of Death. ${ }^{30}$ Death certificates were obtained for $68.5 \%$ (233 out of 340 ) of the patients. Their accuracy as a means of judging the incidence of parkinsonism in the general population may be evaluated from the fact that only 15\% ( 35 out of 233) of these certificates listed parkinsonism as the underlying cause of death, and only $46.4 \%$ ( 108 out of 233 ), as a contributing cause of death. In Williams' study parkinsonism was classified as the primary cause of death in one-third to one-half of the death certificates which noted the disease. ${ }^{31}$ Parkinsonism was omitted from death certificates of almost $40 \%$ of these parkinsonian patients. 


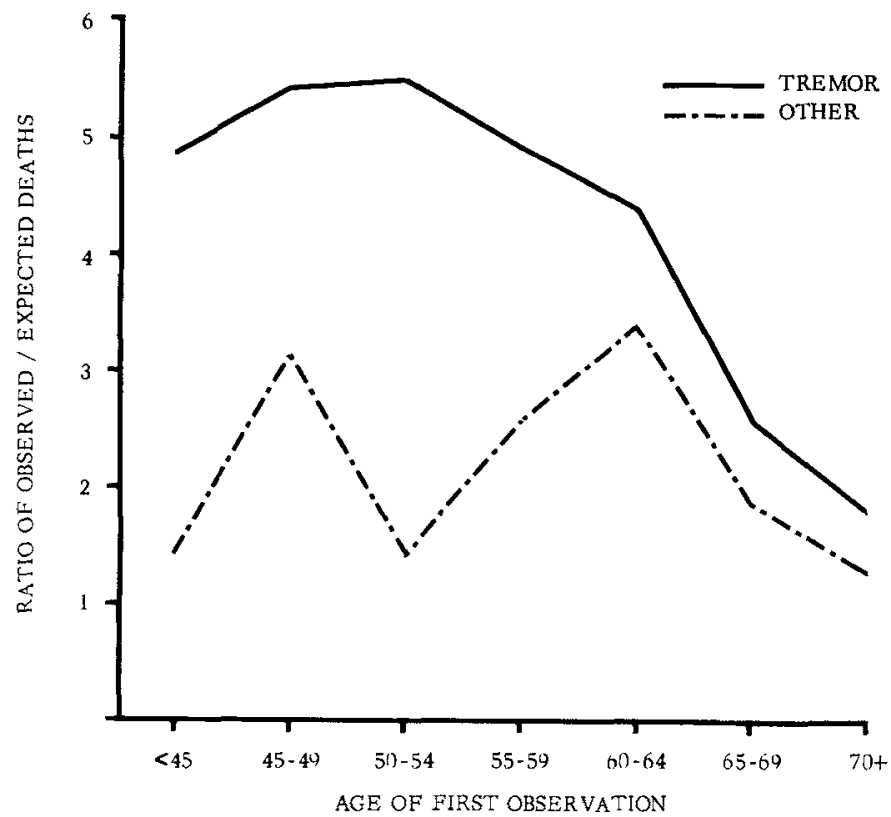

Fig. 4. Ratio of observed to expected deaths among 160 patients with primary parkinsonism with an onset by tremor and 110 patients with an onset by rigidity, slowness, or other non-tremor manifestation. All patients seen within two years of onset
Underlying causes of death as recorded on death certificates of patients in this study are tabulated in Column $A$ of Table 10. The deaths of $14.6 \%$ of these patients were designated on their death certificates as "due to" parkinsonism. The 7 leading underlying causes of death in the remaining 198 patients, compared with those of the general population of New York City during the same years, ${ }^{32}$ are also tabulated in Table 2.

The underlying cause of death on the death certificate is not always satisfactory as a means of evaluating the clinical picture. We have found that death certificates are frequently inaccurate. In addition, in a study such as this, the mortal conditions to which the patient is subject, the mode of dying, and the immediate cause of death are often as important as the underlying cause. For example, benign prostatic hypertrophy would be considered the underlying cause of death on the following death certificate: [I] (a) Bronchopneumonia, secondary to (b) transurethral prostatectomy for (c) benign prostatic hypertrophy. [II] Parkinson's disease. However, if, from examination of medical records, it is apparent that bronchopneumonia was the result of exaggerated postoperative immobility because of the patient's parkinsonism rather than a complication of the trauma of surgery per se, postoperative bronchopneumonia and surgery are both more pertinent as causes of death in this study of parkinsonism than is prostatic hypertrophy. Therefore, the death certificates, physicians' reports, hospital records, and autopsy findings on each patient were compared. The most pertinent causes of death were evaluated and are listed in columns $\mathrm{B}$ and $\mathrm{C}$ of Table 10 . In 34 instances the cause of death could not be limited to a single factor. In these cases the longer standing condition is listed in column $\mathrm{B}$ and that of shorter duration in column $\mathrm{C}$. Parkinson's disease is tabulated as the cause of death only where it was so designated on the death certificate and no other more specific cause could be found in the records. In these patients, generally, the course leading to death was one of increasing inanition and generalized debility. No information about the cause of death was available for 60 of the 340 deaths.

At all ages and for both sexes, the leading causes of death were diseases of the heart, bronchopneumonia, malignant neoplasms, and cerebrovascular accidents. In parkinsonian patients the most striking difference from the general population (Table 11) is the higher incidence of deaths due to bronchopneumonia $(p=.001)$. Certainly this is to be expected in a disease producing chronic immobilizion and debilitation. This was also found in a multiple 
TABLE 10

CAUSES OF DEATH IN 340 PATIENTS WITH PARKINSONISM

\begin{tabular}{|c|c|c|c|}
\hline \multirow[b]{2}{*}{ Cause of death } & \multicolumn{3}{|c|}{$\begin{array}{l}\text { Denformation from } \\
\text { Death } \\
\text { certifi- } \\
\text { cates* All sources } \dagger\end{array}$} \\
\hline & $A$ & $B$ & $c$ \\
\hline Arteriosclerotic heart disease & 62 & 62 & 3 \\
\hline Bronchopneumonia & 30 & 52 & 19 \\
\hline Malignant neoplasms & 24 & 45 & \\
\hline $\begin{array}{l}\text { Vascular lesions of } \\
\text { central nervous system }\end{array}$ & 21 & 36 & 3 \\
\hline Infections of urinary system & 9 & 21 & 2 \\
\hline $\begin{array}{l}\text { Hypertensive cardiovascular } \\
\text { disease }\end{array}$ & 8 & 5 & \\
\hline Generalized arteriosclerosis & 7 & 7 & \\
\hline Accidents & 7 & 4 & \\
\hline Intestinal obstruction & 4 & 5 & \\
\hline Cirrhosis of the liver & 4 & 3 & 1 \\
\hline $\begin{array}{l}\text { Gastrointestinal hemorrhage } \\
\text { due to peptic ulcer or } \\
\text { unknown cause }\end{array}$ & 3 & 6 & 3 \\
\hline Pulmonary embolism & 2 & 7 & 1 \\
\hline Suicide & 2 & 3 & \\
\hline $\begin{array}{l}\text { Therapeutic misadventure in } \\
\text { surgical treatment }\end{array}$ & 2 & 3 & \\
\hline Rheumatic heart disease & 2 & 2 & \\
\hline Tuberculosis & 2 & 1 & \\
\hline Septicemia & 1 & 4 & 2 \\
\hline Acute suppurative cholangitis & 1 & 1 & \\
\hline Ruptured diverticulitis & 1 & I & \\
\hline Addison's disease & 1 & & \\
\hline Schizophrenia & 1 & & \\
\hline Diabetes mellitus & 1 & & \\
\hline Multiple sclerosis & 1 & & \\
\hline Myotonia dystrophica & 1 & & \\
\hline $\begin{array}{l}\text { Central nervous system disease } \\
\text { of unknown etiology }\end{array}$ & 1 & & \\
\hline Postencephalitic parkinsonism & 1 & & \\
\hline Parkinson's disease & 34 & 12 & \\
\hline $\begin{array}{l}\text { No death certificate or other } \\
\text { information on cause } \\
\text { of death available }\end{array}$ & 107 & 60 & \\
\hline Total & 340 & 340 & 34 \\
\hline
\end{tabular}

" "Underlying cause of death" as recorded on death cettificates when available

+Most accurate cause of death as determined from evaluation of physicians" reports, hospital records, death certificates and autopsy reports. In 34 instances, the cause of death could not be limited to a single factor. In these cases, the longer standing condition is listed in column $B$ and that of shorter duration, in column $\mathbf{C}$. cause analysis of a $10 \%$ random sample of deaths registered in England and Wales during the first six months of 1951: The underlying cause of death was pneumonia in $25 \%$ of the 102 death certificates listing paralysis agitans as a complicating or contributing condition. ${ }^{33}$ This difference for parkinsonian patients was less marked in women than in men but was not dependent upon age of the patient or duration of illness. As compared to the general population, in parkinsonian patients at all ages and of both sexes urinary infection was added as one of the 7 leading causes of death, and diabetes mellitus was dropped. There was a higher proportion of women between 45 and 64 dying from accidental injuries. In deaths occurring between the ages of 45 and 64 , cirrhosis of the liver was dropped and peptic ulcer added to the list of the 7 leading causes of death. In a recent study, Strang also found a positive relationship between peptic ulceration and parkinsonism. ${ }^{34}$

At all ages and in both sexes there were fewer patients dying from heart diseases than in the general population of New York City. It is difficult to evaluate accurately the incidence of atherosclerosis in a population, and it has been the impression of many investigators that atherosclerosis plays little role in the pathogenesis of Parkinson's disease ${ }^{35-38}$ Eadie and Sutherland failed to demonstrate any significant excess of clinically detectable arteriosclerotic disease in patients with parkinsonism over matched control subjects, ${ }^{39}$ and in this study the lower proportion of parkinsonian patients dying from diseases of the heart is probably significant. However, in men between 45 and 64 , the proportion of deaths due to vascular lesions of the central nervous system was significantly higher than in the general population.

Especially in the younger ages the proportion of parkinsonian men dying from malignant neoplasms is somewhat lower than in the population as a whole. In the British Multiple Cause Analysis of 1951 the underlying cause of death was malignant neoplasm in only $2 \%$ of those patients with parkinsonism as a contributory condition. ${ }^{33}$ Doshay in 1954 stated that "cancer is phenomenally rare in paralysis agitans." 40 Barbeau and Joly also found a much lower incidence of malignancy among 
their patients than expected.41 Westlund and Hougen, on the other hand, found 6 deaths due to cancer in a group of 111 patients dying with typical paralysis agitans, against an expected 2 deaths. ${ }^{42}$ This latter report is more in agreement with the present study in which there is no evidence that patients with parkinsonism are resistant to malignancies. Almost one-fifth of these patients (or 62 out of 340 ) are known to have had a malignancy at some time in their lives, and 7 of these had multiple primaries. Malignant neoplasm was found to be the cause of death in 45 of the 280 known causes of death. In addition, and in contrast to Barbeau's series, over a third of the parkin- sonian patients dying with malignancies were women, and neoplasms of the breast, larynx, uterus, lung, and hemopoietic system were present. The distribution of the malignancies is given in Table 12.

Nine percent of the deaths occurred following an operative procedure, including 8 after stereotactic procedures for parkinsonism and 17 after other operations. Only 3 were due to direct complications of the surgical procedure: one patient died from hemorrhage following laceration of the hepatic artery during a cholecystectomy and 2, from cerebral hemorrhages during thalamotomy. These are the only deaths listed as "due to" surgery in column B

TABLE 11

SEVEN LEADING CAUSES OF DEATH* IN PARKINSON PATIENTS AND IN THE GENERAL POPULATION OF NEW YORK CITY

\begin{tabular}{|c|c|c|c|c|c|c|c|c|}
\hline & & & & & & $-W$ & men & -2 \\
\hline $\begin{array}{l}\text { New York } \\
\text { Number }\end{array}$ & $\begin{array}{l}k \text { City } \\
\text { Percent }\end{array}$ & $\begin{array}{l}\text { Parkinson } \\
\text { Number }\end{array}$ & $\begin{array}{r}\text { patientst } \\
\text { Percent }\end{array}$ & Age at death: $45-64$ years & $\begin{array}{l}\text { Parkinson } \\
\text { Number }\end{array}$ & $\begin{array}{r}\text { patients } \dagger \\
\text { Percent }\end{array}$ & $\begin{array}{l}\text { New York } \\
\text { Number }\end{array}$ & $\begin{array}{l}\text { K City } \\
\text { Percent }\end{array}$ \\
\hline 115,812 & 46.4 & 15 & 30.0 & Diseases of the heart & 8 & 42.0 & 54,089 & 36.5 \\
\hline 6,787 & 2.7 & 10 & 20.0 & Pneumonia and influenza & 3 & 15.8 & 3,117 & 2.1 \\
\hline 56,783 & 22.7 & 5 & 10.0 & Malignant neoplasms & 4 & 21.1 & 49,925 & 33.6 \\
\hline 10,830 & 4.3 & 6 & 12.0 & $\begin{array}{l}\text { Vascular lesions of central } \\
\text { nervous system }\end{array}$ & 1 & 5.3 & 10,092 & 6.8 \\
\hline 9,028 & 3.6 & 3 & 6.0 & Accidents & 2 & 10.5 & 2,983 & 2.0 \\
\hline & & 2 & 4.0 & Urinary infections & & & & \\
\hline & & 2 & 4.0 & Peptic ulcer & & & & \\
\hline 10,637 & 4.3 & & & Cirrhosis of the liver & & & 4,665 & 3.1 \\
\hline 3,570 & 1.4 & & & Diabetes mellitus & & & 4,692 & 3.2 \\
\hline 36,491 & 14.6 & 7 & 14.0 & Other & 1 & 5.3 & 18,864 & 12.7 \\
\hline 249,938 & 100.0 & 50 & 100.0 & Total & 19 & 100.0 & 148,427 & 100.0 \\
\hline & & & & Age at death: 65 and over & & & & \\
\hline 179,945 & 51.9 & 33 & 39.8 & Diseases of the heart & 14 & 33.3 & 177,269 & 54.2 \\
\hline 12,558 & 3.7 & 12 & 14.5 & Pneumonia and influenza & 4 & 9.6 & 11,481 & 3.5 \\
\hline 67,383 & 19.4 & 9 & 10.8 & Malignant neoplasms & 6 & 14.3 & 52,857 & 16.1 \\
\hline 27,537 & 7.9 & 9 & 10.8 & $\begin{array}{l}\text { Vascular lesions of central } \\
\text { nervous system }\end{array}$ & 5 & 11.9 & 36,096 & 11.0 \\
\hline & & 4 & 4.9 & Urinary infections & 3 & 7.1 & & \\
\hline 6,593 & 1.9 & 3 & 3.6 & Generalized arteriosclerosis & 3 & 7.1 & 8,509 & 2.6 \\
\hline 8,452 & 2.4 & 2 & 2.4 & Accidents & 2 & 4.8 & 8,805 & 2.7 \\
\hline 5,581 & 1.6 & & & Diabetes mellitus & & & 9,613 & 2.9 \\
\hline 38,923 & 11.2 & 11 & 13.2 & Other & 5 & 11.9 & 22,757 & 7.0 \\
\hline 346,972 & 100.0 & 83 & 100.0 & Total & 42 & 100.0 & 327,387 & 100.0 \\
\hline
\end{tabular}

* Seven leading causes of death in each age group arranged in order of importance for Parkinson patients of both sexes combined, followed by those for the population of New York City

†Death certificates were obtained on 233 patients with parkinsonism. Omitted from this tabulation are 35 patients with an underlying cause of death tabulated as parkinsonism and 4 female patients whose death occurred before the age of 45 ; their underlying causes of death were bronchopneumonia, arteriosclerotic heart disease, intestinal obstruction, and rheumatic heart disease.

$\neq$ Obtained from Summary of Vital Statistics. ${ }^{32}$ 
of Table 10. Two other patients had surgery for conditions severe enough to have caused death in themselves: One died after evacuation of an intracerebral hematoma and the other, from gastrointestinal hemorrhage after surgery for a pancreatic carcinoma. The remaining 20 deaths occurred after otherwise uncomplicated surgery and were mostly due to pneumonia and other infections. Considering accidental injury, only 4 patients had injuries severe enough to cause death. Deaths in an additional $4 \%$ (11) of the patients followed fracture of the hip, with pneumonia the immediate cause of death, secondary to immobilization for the injury superimposed on that of Parkinson's disease. Death certificates were found to be inconsistent in selection of the underlying cause of death. In column A of Table 10 these patients are distributed among: surgical deaths, accidental deaths, the condition for which surgery was performed, and the immediate cause of death; they are recorded exactly as listed on death certificates. In columns B and $C$ they are listed under the immediate cause of death if the injury, underlying condition, or surgical technique was not the prime factor in precipitating death. Thus, $11 \%$ (31 out of 280 ) of the patients with known causes of death died after operations or accidents which were uncomplicated except for their parkinsonism. Unfortunately, no com-

TABLE 12

SITES OF MALIGNANT NEOPLASMS*

\begin{tabular}{lr}
\hline Gastrointestinal tract & 19 \\
Uterus and ovaries & 7 \\
Breast & 6 \\
Hemopoietic system & 6 \\
Lung & 5 \\
Pancreas & 5 \\
Skin & 5 \\
Prostate & 5 \\
Brain and spinal cord & 3 \\
Bladder & 2 \\
Gall bladder & 1 \\
Bone & 1 \\
Larynx & 1 \\
Unknown primary site & 3 \\
\multicolumn{1}{c}{ Total } & 69 \\
\hline
\end{tabular}

* Recorded in 62 out of 340 known deaths among parkinsonian patients parable figures from the general population are available.

\section{SUMMARY}

1. A practical classification of the types of parkinsonism (primary, secondary, and indeterminate) is presented along with a system for grading severity into 5 stages. The natural history of the syndrome of parkinsonism was studied in 802 patients followed in the Vanderbilt Clinic during the period 1949 to 1964 .

2. Two-thirds of all patients with primary parkinsonism have their onset of illness between the ages of 50 and 69. In this study the age at onset was the same in men and women. The gradual shift to an older age distribution in recent years is discussed.

3. Approximately one-quarter of the patients with Parkinson's disease who had their disease for less than five years were already severely disabled or dead. By five to nine years this had increased to two-thirds and by ten to fourteen years' duration, to over $80 \%$. Among patients with primary parkinsonism there is a small group of atypical patients who, with slow evolution of the disease process, maintain balance and righting reflexes for ten or more years and are not severely disabled for twenty or more years.

4. Within the limits of the data examined, there were no definitely significant correlations among sex of the patient, age at onset of the disease, severe infections or other events preceding the onset of parkinsonism, positive family history of parkinsonism or other neurological disease, and the rate of progression of the disease.

5. Tremor is most frequently the initial symptom. There is some indication that, at least during the first ten years of illness, parkinsonism with tremor as the initial symptom progresses more slowly than parkinsonism with other heralding symptoms.

6. Parkinsonism does shorten life and does so substantially, regardless of the age at onset or the type of parkinsonism. The observed mortality is three times that of the general population of the same age, sex, and color.

7. The relative mortality risk is less for men than women and less for those in whom tremor was the initial symptom rather than rigidity, 
bradykinesia, or other non-tremor manifestation.

8. There is no evidence that the introduction of newer methods of medical treatment and supportive care has substantially prolonged life. For patients treated surgically, follow-ups are not yet sufficiently long to indicate a trend.

9. Bronchopneumonia and urinary infections are causes of death more frequently in parkinsonian patients of all ages than they are in the general population. In certain age and sex groups of parkinsonian patients there are also more deaths due to accidental injury, peptic ulcer, and vascular lesions of the central nervous system.

10. There is no evidence that patients with parkinsonism are in any way resistant to malignant neoplastic disease.

The authors wish to thank Dr. Roger C. Duvoisin for his helpful suggestions and clinical assistance, Dr. Myrna J. Schear and Dr. James Reilly for their aid in examining patients and recording data, Dr. Morton D. Schweitzer for statistical advice, and Mrs. Francis Heytink and Miss Barbara Binkert for their technical assistance.

\section{REFERENCES}

1. Parkinson, I.: An Essay on the Shaking Palsy. London: Sherwood, Nesly \& Jones, 1817.

2. CHARGOT, J. M.: De la paralysie agitante. Leçons sur les Maladies du Systeme Nerveux, Recueillies et Publiées par Bourneville, Paris. 1:155, 1880.

3. ERB, w.: Paralysis agitans. Dtsch. Klinik 6:31, 1901.

4. HART, T. S.: Paralysis agitans: some clinical observations based on the study of 219 cases seen at the clinic of Prof. M. A. Starr, J, nerv. ment. Dis. 31: $177,1904$.

5. Manschot, c. w.: Paralysis Agitans. Amsterdam: van Rossen, 1904.

6. MENDEL, k.: Die Paralysis Agitans. Berlin: Verlag von S. Karger, 1911.

7. DINSDALE, F.: Changes in the parkinsonian syndrome in the twentieth century. Quart. J. Med. 15:39:155, 1946.

8. WILson, s. A. K.: Neurology. Baltimore: Williams \& Wilkins Co., 1955, p. 922

9. SCHWAB, R. S., DOSHAY, L. J., GARLAND, H., BRADSHAW, P., GARVEX, E., and CRAWFORD, B.: Shift to older age distribution in parkinsonism. Neurology (Minneap.) $6: 783,1956$.

10. FIELDs, w. s.: Pathogenesis and Treatment of Parkinsonism. Springfield: Charles C Thomas, 1958.

11. scrwab, R. S.: Progression and prognosis in Parkinson's disease. J. nerv. ment. Dis. 130:556, 1960.

12. Poskanzer, D. C., and SChWAB, R. S.: Studies in the epidemiology of Parkinson's disease predicting its disappearance as a major clinical entity by 1980 . Trans. Amer, neurol. Ass. 86:234, 1961 .

13. DUvoISIN, R. C., YAHR, M. D., SCHWETTZER, M. D., and meratr, H. H.: Parkinsonism before and since the epidemic of encephalitis lethargica. Arch. Neurol. (Chic.) $9: 232,1963$
14. puvorsin, R. C., and YAHR, M. D.: Encephalitis and parkinsonism. Arch. Neurol. (Chic.) 12:227, 1965.

15. Mjönes, H.: Paralysis Agitans. Copenhagen: Ejnar Munksgaard, 1949

16. hantmann-von Monakon,, k.: Das Parkinson-Syndrom. Basel: S. Karger, 1960.

17. Gowers, w. R.: A Manual of Diseases of the Nervous System, ed. 2. Philadelphia: Blakiston, 1893, p. 636.

18. PAthick, H. T., and LEvx, D. M.: Parkinson's disease. A clinical study of one hundred and forty-six cases. Arch. Neurol. Psychiat. (Chic.) 7:611, 1922.

19. Alpers, B. J.: Clinical Neurology. Philadelphia: F. A. Davis Co., 1963.

20. DANA, C. L.: Hereditary tremor: a hitherto undescribed form of motor neurosis. Amer. J. med. Sci. 94:396, 1887.

21. CRITChLEy, M.: Observations on essential (heredofamilial) tremor. Brain 72:9, 1949.

22. JAGER, B. V., and KING, T.: Hereditary tremor. Arch. intern. Med. 95:788, 1955.

23. LARSSON, T., and sJoGreN, T.: Essential tremor, a clinical and genetic population study. Acta psychiat. scand. Suppl. 144. 36:1, 1960.

24. MARShaLL, J.: Observations on essential tremor. $T$. Newrol. Neurosurg. Psychiat. 25:122, 1962.

25. DAvis, C. H., and KUNKLE, E. C.: Benign essentia (heredofamilial) tremor. Arch. intern. Med. 87:808, 1963.

26. KURLAND, L. T.: Pathogenesis and Treatment of Parkinsonism. Springfield, Illinois: Charles $\mathrm{C}$ Thomas, 1958 , p. 1 .

27. FEGISTRAR GENERAL: Annual report of births, deaths, and marriages in England and Wales. London: Gen eral Register Office, 1855-1860.

28. U.s. PUBLIC HEALTH SERvice: United States Life Tables. Washington, D.C.: U.S. Department of Health, Education, and Welfare, Vol, 1, No. 1, 1959-1960.

29. ox JoNG, p.: Parkinson's disease: statistics. J. Neurosurg. 2:149, 1966.

30. world FEALTH ORGANIzATION: Manual of the international statistical classification of diseases, injuries, and causes of death. $1: 357,1957$.

31. Williams, G. R.: Morbidity and mortality in parkinsonism. J. Neurosurg. 24:138, 1966.

32. CITY OF NEW YORK, DEPARTMENT OF HEALTH: Summary of vital statistics, 1950-1964.

33. FEGISTRAR GENERAL: Statistical review of England and Wales for the year 1951. Medical certification of causes of death. Multiple cause analysis. London: General Register Office, 1953, p. 250.

34. STRANG, R. R.: The occurrence of peptic ulceration in patients with parkinsonism. Acta neurol. scand. 42 : $124,1966$.

35. Schwab, R. S., and england, A, C.: Parkinson's disease. J. chron. Dis. 8:488, 1958 .

36. Haymaker, w.: In: The Shaking Palsy, A Symposium, edited by $H$. Elliott and B. Nashold. Montreal: McGill University, $1959, \mathrm{p}, 18$.

37. heyman, A.: In: The Shaking Palsy. A Symposium, edited by $H$. Elliott and $B$. Nashold. Montreal: McGill University, 1959 , p. 21.

38. HowerL, D.: In: The Shaking Palsy A Symposium, edited by $H$. Elliott and B. Nashold. Montreal: McGil University, 1959, p. 17 .

39. EADIE, M, $y$. , and sUTHERIAND, J. M.: Arterjosclerosis in parkinsonism. J. Neurol. Neurosurg. Psychiat. 27: 237,1964

40. Doshay, L. J.: Problem situations in the treatment of paralysis agitans. J. Amer. med. Ass. 156:680, 1954.

41. barbeau, A., and joxy, J.: Parkinson et cancer. L'Union Med. du Canada 92:169, 1963.

42. Westulnd, $k$, and hougen, A.: Cancer as a cause of death among patients with other chronic diseases. I Amer. med. Ass. 162:1003, 1956. 


\section{Neurology}

\section{Parkinsonism: onset, progression, and mortality Margaret M. Hoehn and Melvin D. Yahr Neurology 1967;17;427 \\ DOI 10.1212/WNL.17.5.427}

This information is current as of May 1, 1967

\section{Updated Information \&} Services

Citations

Permissions \& Licensing

Reprints including high resolution figures, can be found at:

http://n.neurology.org/content/17/5/427.citation.f ull

This article has been cited by 100

HighWire-hosted articles:

http://n.neurology.org/content/17/5/427.citation.f ull\#\#otherarticles

Information about reproducing this article in parts (figures,tables) or in its entirety can be found online at:

http://www.neurology.org/about/about_the_journ al\#permissions

Information about ordering reprints can be found online:

http://n.neurology.org/subscribers/advertise

Neurology ${ }^{\circledR}$ is the official journal of the American Academy of Neurology. Published continuously since 1951, it is now a weekly with 48 issues per year. Copyright (C) 1967 by the American Academy of Neurology. All rights reserved. Print ISSN: 0028-3878. Online ISSN: 1526-632X.

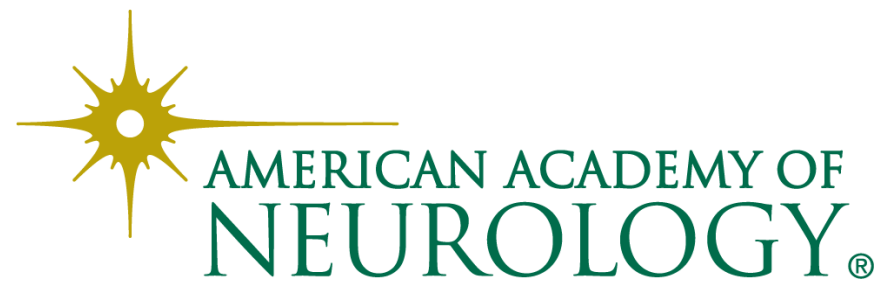

